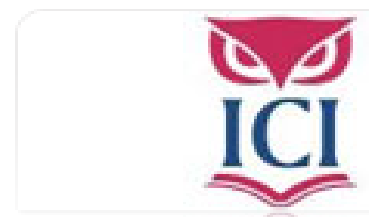

IUS. Revista del Instituto de Ciencias Jurídicas de Puebla A.C.

ISSN: 1870-2147

revista.ius@hotmail.com

Instituto de Ciencias Jurídicas de Puebla A. C.

México

Arias Castaño, Abel

Acuerdos y desacuerdos en el proceso de construcción europea: el Tratado de Lisboa de 13 de diciembre de 2007

IUS. Revista del Instituto de Ciencias Jurídicas de Puebla A.C., núm. 22, 2008, pp. 281-291 Instituto de Ciencias Jurídicas de Puebla A. C.

Puebla, México 


\section{ACTUALIDAD EUROPEA}

El presente texto es una crónica sobre losavataresquesufreen Europa elTratado de Lisboa respecto a su ratificación,entrelosquecuentaelreferéndum negativoenIrlanda,complicacionesjurídicas en el Reino Unidoyla aparición deunnuevoobstáculoalaratificación en otro de los estados miembros más euroescépticos: Polonia

\section{Acuerdos y desacuerdos en el proceso de construcción europea: el Tratado de Lisboa de} 13 de diciembre de 2007

Abel Arias Castaño*

$\mathrm{E}$ stos apuntes toman el testigo temporal del trabajo publicado por María Valvidares en el número 20 de ius. En aquella ocasión, bajo un sugerente y atinado título ("Un fantasma recorre Europa: el fantasma de la soberanía"), la profesora Valvidares se ocupaba de explicar las claves esenciales del -sin ningún género de dudas- acontecimiento más importante que entonces se estaba viviendo en el seno de la Unión Europea (en adelante UE): el Consejo Europeo celebrado en Bru-

* Área de Derecho Constitucional, Universidad de Oviedo. selas el 21 y el 22 de junio de 2007, y la convocatoria de una Conferencia Intergubernamental destinada a discutir y redactar un Proyecto de Tratado, que permitiese a la UE salir del proceso de crisis e incertidumbre provocado por el "No" a la llamada Constitución Europea en los referendos de Francia y Holanda de 2005.

Unos meses después, en el momento en que se está redactando esta nueva entrega de la "Crónica de la actualidad política, jurídica e institucional de la UE", dos son las grandes noticias en Europa. Por un lado, la finalización de los trabajos de esa Conferencia Intergubernamental, con la firma del conocido como Tratado de Lisboa el 13 de diciembre de 2007. Por otro, las complicaciones surgidas en el proceso de ratificación del texto tras el triunfo de los euroescépticos en el referéndum celebrado en Irlanda el 12 de junio de 2008. El objeto de las siguientes líneas será ofrecer una panorámica detallada de esos dos importantes episodios. Tres son las ideas esenciales que quieren destacarse al respecto en este artículo:

La primera -de carácter meramente introductorio y contextualizador- es recordar al lector no familiarizado con los asuntos europeos que, en realidad, cuando nos referimos al Tratado de Lisboa no 
lo estamos haciendo a un nuevo tratado, con sustantividad normativa propia, que haya que añadir a la lista de los Tratados Constitutivos de la uE, sino a un hito legislativo cuyo único objeto es proceder a revisar de manera muy profunda y significativa algunos de los textos ya existentes. De esa manera $-\mathrm{y}$ dada la complejidad técnica de las reformas introducidas- tan importante -o más- que el articulado del Tratado de Lisboa en sí mismo considerado, será manejar las nuevas versiones oficiales consolidadas de los tratados que se modifican. En ese sentido, resulta de interés apuntar que tales textos consolidados se encuentran disponibles desde el pasado 16 de abril de 2008 en las páginas oficiales de la UE en internet (Véase, http://europa.eu/lisbon_ treaty/index_es.htm), y que el 9 de mayo se ha procedido a publicar su versión impresa en el Diario Oficial de la UE.

La segunda observación es que, realmente, en el Tratado de Lisboa se plasma muy fielmente lo ya acordado -en forma de mandato dirigido a la Conferencia Intergubernamental- en la Cumbre Europea de Bruselas del mes de junio de 2007. Los cambios introducidos por los brevísimos trabajos de la Conferencia Intergubernamental (celebrados entre el 24 de julio al 28 de septiembre de 2007) han resultado, en ese sentido, poco significativos tanto desde un punto de vista cuan- titativo como cualitativo, y no han alterado, en absoluto, la filosofía diseñada en la referida cumbre. Se trata de modificaciones que resuelven algunos problemas técnicos, o que responden a las habituales batallas y escaramuzas políticas de última hora por parte de los estados para conseguir la mayor representación posible en las instituciones.

Muestras de lo primero sería la inclusión de un protocolo en el cual se prevé que el Consejo de Ministros únicamente podrá enmendar una decisión tomada de conformidad con las reglas anteriores a las establecidas en el Tratado de Lisboa tras la autorización por unanimidad del Consejo europeo. Y, también, la adopción de una declaración sobre la designación del alto representante de la Unión para Asuntos Exteriores y Política de Seguridad en el periodo transitorio que pudiera producirse desde la entrada en vigor del Tratado hasta la investidura de la Comisión.

Ejemplos, por su parte, de lo segundo serían la ligera modificación del número máximo de miembros del Parlamento Europeo (de 750 a 751) cuya beneficiaria directa será Italia, que ve satisfechas de esa manera sus pretensiones de aumentar -como Francia y Reino Unido- su número de diputados europeos. 0 la variación en el número de abogados generales de ocho a once, que, en el fondo, no tiene otro sentido que permitir a la "euroescéptica" Polo- 
nia (al igual que ya sucede con Alemania, Francia, Reino Unido, Italia y España) contar con un abogado permanente en el Tribunal de Justicia de la Unión Europea.

A grandes rasgos $-\mathrm{y}$ remitiéndonos para detalles más concretos sobre este punto al ya mencionado trabajo de la profesora Valvidares, que conserva plena vigencia- podemos sintetizar el sentido y contenido esencial del Tratado de Lisboa en las cuatro notas siguientes:

1) Desmantelar y borrar, por completo, del texto del nuevo Tratado todos aquellos indicios presentes en el fallido Proyecto de Constitución Europea que apuntaran, de algún modo, a la apertura de un proceso constitucional, y/o que pudieran hacer vislumbrar el primer paso hacía la construcción de un "superestado" europeo de índole federal. Tal tendencia se concreta en diferentes detalles concretos de muy diferente naturaleza. Así, en un plano estrictamente jurídico, resulta muy significativo observar cómo el artículo previsto en el Proyecto de Constitución Europea $-\mathrm{y}$ presente, por otra parte, en cualquier estructura federal- que consagraba la primacía del derecho de la federación (en este caso de la ue) sobre el derecho de los estados miembros, ha dejado de formar parte del articulado del Tratado de Lisboa y se ha trasladado a una declaración anexa sin pleno valor jurídico. En un plano simbólico, desaparecen del Tratado los artículos que regulaban la bandera o el himno de la Unión. Y en un plano terminológico, cabe destacar cómo del nombre mismo del Tratado se elimina cualquier referencia a una supuesta naturaleza "constitucional"; cómo se vuelve a la vieja nomenclatura en materia de fuentes (se seguirá hablando de "Reglamento" y "Directiva" en lugar de "Ley" y "Ley marco" como se preveía en el Proyecto de Constitución Europea); o cómo -en definitiva- se prefiere la barroca designación de alto representante de la Unión para Asuntos Exteriores y de Política de Seguridad, en lugar de la más simple de ministro de Asuntos Exteriores de la ue.

2) Establecer -en consonancia con lo explicado en el apartado anterior- una serie de mecanismos destinados a frenar la acción de la ue. Es precisamente desde esa finalidad como debe interpretarse, por poner algún ejemplo, la especificación en el articulado de una especie de "cláusula de reversión de competencias" a los estados, en tanto que éstas no sean efectivamente ejercitadas por la Unión. Tal cláusula parece partir de la discutible idea de considerar que las competencias únicamente se ejercen por acción y no por omisión, y se concreta técnicamente en la previsión de que "los estados miembros volverán a ejercer su competencia en la medida en que la Unión haya dejado de ejercer la suya”. 
En la misma línea, y debido fundamentalmente a las presiones de Holanda, se refuerza el papel de los parlamentos nacionales que -dentro de la genérica función de "contribuir activamente al buen funcionamiento de la Unión" que les atribuye expresamente el Tratado de Lisboaejercen una importante competencia en el control de la subsidiariedad de derecho comunitario. De esa manera el conocido como "sistema de alerta temprana”, ya previsto en el Proyecto de Constitución Europea, se modifica, en el texto de Lisboa, en un aspecto esencial: las discrepancias de criterio que puedan existir entre la mayoría simple de los parlamentos nacionales y la Comisión no serán resueltas por el Tribunal de Justicia de la UE, sino por el Consejo de Ministros y/o el Parlamento Europeo. De un control jurisdiccional de la subsidiariedad se pasa así a un control esencialmente político de la misma.

3) Introducir una serie de cambios sustanciales en la composición $\mathrm{y}$ en el funcionamiento de las instituciones que resultaban absolutamente indispensables tras la reciente ampliación de la uE a 27 estados. Sin ánimo de ser exhaustivos, y a título meramente ejemplificativo, podrían citarse aquí:

- La extensión del procedimiento de codecisión entre el Parlamento Europeo y el Consejo que sitúa al primero en una verdadera posición de "colegislador".
- El establecimiento de un nuevo sistema de votación de mayoría doble en el seno del Consejo, que se convierte $-y$ esto es muy importante- en el procedimiento ordinario, salvo en los casos en los que expresamente se prevea lo contrario. La mayoría cualificada se alcanzará con un mínimo del $55 \%$ de los estados miembros, que incluya al menos a quince de ellos y represente, al menos, al $65 \%$ de la población de la Unión.

- La conversión del Consejo Europeo en una institución comunitaria más, terminándose, además, con el sistema de las presidencias rotatorias cada seis meses actualmente empleado.

- La previsión de que, a partir de 2014, el número de miembros que compondrán la Comisión será únicamente de dos tercios del número de estados miembros.

- La aparición de un alto representante de la Unión para Asuntos Exteriores y Política de Seguridad que será el jefe de la diplomacia europea, y que será nombrado por el Consejo Europeo por mayoría cualificada, con el acuerdo del presidente de la Comisión.

- La creación de nuevas salas jurisdiccionales especializadas, siguiendo el modelo de la ya existente en materia de Función Pública. Unas salas que, junto al Tribunal de Justicia de la ue y al Tribunal de Primera Instancia conforman la arquitectura judicial de la UE. 
4) Incluir en el derecho originario de la UE una mención a aspectos y retos de futuro que han aparecido en los últimos años, y que no habían, ni siquiera, sido incorporados en el Proyecto de Constitución europea. Pensamos por ejemplo, en este apartado, en la previsión de una base jurídica para la lucha contra el cambio climático, o en la igualmente novedosa, mención al "espíritu de solidaridad entre los estados miembros" en la parcela de la política energética cuya principal valedora ha sido Polonia.

No puede olvidarse, en todo caso, que la filosofía general que ha caracterizado la redacción del Tratado de Lisboa ha sido marcar un paso hacía atrás y no hacía delante respecto al citado Proyecto de Tratado Constitucional. Y es, por tanto, precisamente desde esta óptica valorativa general, desde la que deben ponderarse, en su justa medida, esas pequeñas y puntuales aportaciones, sin que deba magnificarse más de lo debido su importancia.

La tercera y última idea que queremos apuntar en esta crónica hace referencia al momento actual en el que se encuentra el Tratado de Lisboa, y a la significación que el mismo tiene en el pasado y en el futuro del proceso de construcción europea. Comencemos este apartado con una puntualización: que el Tratado haya sido firmado el pasado 13 de diciembre de 2007 no quiere decir que ya haya entrado automática- mente en vigor. Para que ello ocurra es necesario que primero, tal y como se prevé en sus disposiciones finales, se proceda a su ratificación por todos los estados miembros. Tal matización no resulta superflua, sobre todo, teniendo en cuenta la historia más reciente y, en concreto, lo acontecido con el fallido Proyecto de Constitución. Después de todo, también en el año 2005 existía un texto ya firmado. Un texto "únicamente" pendiente de ratificación. Y después del "No" del referéndum celebrado en Francia, primero, y en Holanda, más tarde, todo acabó convertido en letra mojada. ¿Podría suceder ahora lo mismo?

Naturalmente la repetición de estos antecedentes era una hipótesis que preocupaba mucho a los gobiernos firmantes del Tratado. Otro fracaso como el del Proyecto de Constitución Europea agudizaría preocupantemente la crisis iniciada en 2005, y convertiría lo que entonces se denominó eufemísticamente como "periodo de reflexión" en un inquietante "periodo de parálisis" sin paliativos ni matizaciones posibles. Tales riesgos hacían necesario simplificar al máximo el proceso de ratificación, intentando asegurar, en la medida de lo posible, la entrada en vigor del Tratado. Una estrategia en la que no encajaban, en absoluto, los siempre impredecibles referendos que tantos problemas habían ocasionado en el pasado, máxime si su celebración, a pesar 
de su gran simbolismo político, no venía obligatoriamente impuesta por las normas constitucionales de los diferentes estados miembros. Por eso, a diferencia de lo que ocurrió con el Proyecto de Constitución Europea, 26 de los 27 Estados de la UE establecieron que la ratificación del Tratado de Lisboa se produjera a través del sistema de votación parlamentaria. Y sólo Irlanda, debido a exigencias peculiares de su sistema constitucional, optó por el mecanismo del referéndum.

Éste era el escenario existente en la UE a comienzos del año 2008. Siguiendo un calendario ideal, las ratificaciones se irían produciendo a lo largo de todo el año, y el Tratado de Lisboa entraría en vigor el 1 de enero de 2009. En teoría se trataba de un proceso con 27 variables o complicaciones posibles, tantas como estados debían ratificar el texto. En la práctica, en cambio, todos los expertos coincidían en apuntar que no todas las ratificaciones resultarían igual de problemáticas. Al contrario, la idea comúnmente compartida era que en toda esta trama existía un hito crucial. Todos los analistas señalaban un lugar y un momento como la verdadera clave de todo el proceso. El lugar era Irlanda, y el momento el 12 de junio de 2008; la fecha en la que el gobierno de ese país había convocado la celebración del referéndum. Si los irlandeses apoyaban mayoritariamente el Tratado de Lisboa, éste podía considerarse ese mismo día, salvo sorpresa mayúscula en algún otro Estado, virtualmente ratificado. Si, en cambio, en Irlanda vencía el "No", el proceso se complicaría, tanto por la necesidad de encontrar una solución a ese escollo, como por el "efecto rebote" que ese resultado podría producir en otros países en los que las ideas euroescépticas se encuentran tradicionalmente muy extendidas. Pues bien, siendo esa la previsión avanzada por los expertos en asuntos comunitarios ya a principios del 2008, el posterior desarrollo de los acontecimientos no ha hecho sino confirmar, por una vez, sus vaticinios.

Hasta el 12 de junio de 2008, los parlamentos de 18 países habían ratificado el Tratado de Lisboa. Quedaban otros ocho, y la incertidumbre de lo que sucediese ese decisivo día en Irlanda. Los resultados confirmaron las tendencias que venían avanzando desde hacía meses algunos sondeos y encuestas electorales. Pese a los esfuerzos de las instituciones comunitarias y de la mayor parte de la fuerzas parlamentarias de Irlanda que desarrollaron una intensa campaña a favor del "Sí", el "No" acabó venciendo en un referéndum que contó con una participación del 53.1\% del censo, y en el que una mayoría del 53. 4\% de los irlandeses se decantó por oponerse a que su país ratificase el texto normativo sometido a consulta.

Durante los siguientes días se 
sucedieron las primeras reacciones políticas. Algunas mostraban una profunda decepción por los resultados del referéndum. Otras, las de los más euroescépticos, la necesidad de analizar profundamente lo sucedido, y de reflexionar sobre la conveniencia de paralizar el proceso de ratificación. Unas y otras fueron la antesala del Consejo Europeo celebrado en Bruselas los 19 y 20 de junio de 2008. Si en Irlanda hubiera vencido el "Sí", este Consejo, previsto desde hacía meses, habría sido, con toda probabilidad, rutinario y trivial. Con el triunfo del "No", se había convertido sencillamente esencial: una reunión en la que los jefes de Estado y de gobierno de la UE debían ser capaces de trazar una hoja de ruta de urgencia que permitiese salvar el Tratado de Lisboa de un naufragio similar al sufrido dos años antes por el Proyecto de Constitución Europea.

Tras largas y difíciles deliberaciones se aprobó un texto de "Conclusiones de la Presidencia”, en el que se contienen las directrices del plan de emergencia frente a la crisis. La estrategia incluye dos medidas diferentes. Por un lado, se conviene "otorgar más tiempo al gobierno irlandés para proponer el camino común a seguir". En concreto, la idea es aplazar el asunto hasta el próximo Consejo Europeo que se celebrará los próximos 15 y 16 de octubre en Francia. Por otro lado, y hasta entonces, se insiste en la ne- cesidad de continuar con el proceso de ratificación en los países donde estos trámites aún no han concluido. Con ello, parecen perseguirse dos finalidades diferentes. En primer lugar, presionar políticamente a Irlanda, convirtiéndolo en el único país que no ha ratificado el Tratado. En segundo lugar, evitar el peligro de que el ejemplo del "No" irlandés pueda extenderse a otros estados en los que las tesis euroescépticas tienen una importante implantación. Un temor a un "efecto rebote" o "sarampión" que ha resultado muy fundado habida cuenta de lo acontecido en las últimas semanas en la República Checa, en el Reino Unido o en Polonia.

Los primeros síntomas de ese "contagio" se hicieron ya claramente visibles durante la propia celebración del Consejo Europeo. La intención inicial de casi todos los estados era fortalecer la confianza en la consecución exitosa de esa segunda parte de la estrategia a través de la aprobación de un texto contundente, que declarase sin más matices que "el Consejo Europeo ha tomado nota de que los parlamentos de 19 estados miembros han ratificado el Tratado y de que el proceso de ratificación continúa en los otros países". Sin embargo, ello no fue posible. La República Checa se opuso firmemente a esa redacción, y forzó que se incluyese en las conclusiones una mención expresa a sus circunstancias concretas. De esa manera, el 
texto finalmente aprobado establece que "El Consejo Europeo ha tomado nota de que los parlamentos de 19 estados miembros han ratificado el Tratado y de que el proceso de ratificación continúa en otros países”. Aclarándose, a continuación, a través de una nota al pie de página, que "El Consejo Europeo ha tomado nota de que la República Checa no puede llevar a término el proceso de ratificación hasta que el Tribunal Constitucional de ese país emita su dictamen sobre la conformidad del Tratado de Lisboa con el ordenamiento constitucional checo". Aparentemente puede parecer que no existen grandes diferencias entre el borrador que se pretendía aprobar, y el texto finalmente aprobado. Sin embargo, sí que las hay. Con esa segunda versión el primer ministro checo, Mirek Topolánek, ha conseguido introducir, aunque sea sutilmente, el mensaje de que su gobierno no se encuentra en condiciones de garantizar que su país vaya a ratificar finalmente el Tratado tanto por la incertidumbre de lo que pueda decidir (previsiblemente en otoño) su Tribunal Constitucional, como por la presión de las importantes fuerzas políticas euroescépticas. Unas posiciones que son defendidas en la República Checa tanto por algunos de los partidos de la oposición, como también por importantes sectores del propio partido en el gobierno, aglutinados, nada más y nada menos, que en torno al presidente de la República Václav Klaus.

Más problemas para la ratificación del Tratado de Lisboa -aunque en este caso parece que se hayan finalmente disipado- aparecían esos mismos días en el Reino Unido. El gobierno laborista de Gordon Brown se vio forzado el 20 de junio, en pleno Consejo Europeo y en medio del vendaval originado por el nuevo "problema checo", a paralizar momentáneamente el proceso de ratificación del Tratado. El poder ejecutivo debía esperar a que un órgano jurisdiccional británico se pronunciase sobre la demanda de un ciudadano que consideraba al gobierno jurídicamente obligado a realizar un referéndum en la Isla. Durante días la expectación fue máxima. Si el Tribunal estimaba la demanda, el Tratado de Lisboa podía considerarse definitivamente muerto, pues todos los expertos coincidían en pronosticar que si se tuviese que celebrar en el Reino Unido un referéndum sobre esta materia en esos momentos el "No" vencería con prácticamente total seguridad. Sin embargo, los argumentos del demandante, el millonario próximo al partido conservador Stuart Wheeler, fueron rechazados en una contundente sentencia dictada el 25 de junio. Los partidarios del Tratado pudieron entonces respirar tranquilos y más aún cuando, tras conocer este pronunciamiento judicial, el gobierno británico (que ya contaba 
con las preceptivas aprobación del Parlamento y aceptación de la reina para llevar a cabo la ratificación del Tratado) anunciaba que cumpliría la última de las formalidades pendientes (el depósito de los instrumentos en Roma) a mediados de julio, sin esperar a que el fallo se convirtiera en firme, y/o se resolvieran los posibles recursos que frente al mismo pudiesen plantearse.

Sin embargo, el "efecto rebote" del "No irlandés" no parece haber cesado aún completamente. Cuando se está terminando de redactar esta crónica la última novedad es la aparición de un nuevo obstáculo a la ratificación en otro de los estados miembros más euroescépticos: Polonia. El presidente de la República, Lech Kaczynsky, ha anunciado en una entrevista concedida al diario Dziennik, publicada el 1 de julio, que el Tratado de Lisboa no tiene sentido después del resultado del referéndum del 12 de junio, y que, por tanto, no lo firmará hasta que no se sepa que va a ser ratificado también por Irlanda. Sus declaraciones han generado una intensa discusión jurídica en Polonia sobre la extensión de los poderes de veto que la Constitución polaca atribuye al presidente de la República. Mientras que algunos consideran que este privilegio se extiende únicamente a algunas leyes, pero no a los tratados internacionales, otros defienden que la posición de Kaczynsky es jurídicamente legítima, y que tiene un claro fundamento constitucional. De esa manera, parece que al "problema irlandés", y al "problema checo", podría haber que añadir también un "problema polaco", como otra variable a tomar en consideración en los próximos meses. Con carácter provisional, y tomando sus análisis con la máxima prudencia, puede apuntarse, en todo caso, que los primeros especialistas que se han ocupado de este asunto han interpretado las declaraciones del presidente Kaczynsky como una simple maniobra política para reconciliar a su partido con el electorado más euroescéptico después del varapalo sufrido en las elecciones parlamentarias de noviembre de 2007, y vaticinan que acabará reconsiderando su postura, y firmando un Tratado que, por otra parte, ya fue aprobado por una aplastante mayoría del Parlamento polaco el 1 de abril de 2008.

Este es, a grosso modo, el "movedizo" estado en el que se encuentra el proceso de ratificación del Tratado de Lisboa en los primeros días de julio de 2008. Así las cosas, resulta, en estos momentos, muy difícil predecir el destino que correrá finalmente el Tratado. Al margen de algunas certezas -como el descartar por completo que pueda entrar en vigor en la fecha en la que se había pensado inicialmente (1 de enero de 2009) - cualquier conjetura sobre lo que pueda suceder en los próximos meses pertenece al terre- 
no de la pura adivinanza política. Existen, en todo caso, dos grandes escenarios posibles. El primero es que en el momento de celebrarse el Consejo Europeo de octubre, el "efecto rebote" del referéndum en otros países haya sido encauzado, y el único problema a resolver sea el de Irlanda. En tal situación, lo previsible es que el gobierno de Dublín acepte convocar un nuevo referéndum en junio de 2009 -coincidiendo con las elecciones al Parlamento Europeo que se celebrarán en esa fecha- o si fuese posible, unos meses antes. Para cambiar el sentido del voto, y hacer factible la victoria del "Sí" habría que incorporar, en todo caso, una serie de "protocolos explicativos", o de "declaraciones" al texto que se sometiera a consulta. En ellos podría contenerse una mención clara y expresa a una serie de aspectos que, si bien paradójicamente no pretenden ser reformados a través del Tratado de Lisboa, parece que han sido decisivos para el triunfo del "No". En tal grupo, se podrían incluir garantías como que la ratificación del Tratado no compromete, por ejemplo, la posición de Irlanda acerca del aborto, ni su neutralidad, ni determinadas peculiaridades de su régimen fiscal. En una situación extrema, podría llegar a negociarse alguna cláusula que matizase o demorase la desaparición de los "comisarios nacionales" (al ser ésta otra cuestión que ha provocado muchos recelos entre los irlandeses). En ese caso, habría que encontrar una fórmula indirecta para introducir tal modificación, sin tener que alterar el texto del Tratado. Ello haría necesario tener que comenzar de nuevo con el proceso de ratificación en todos los países. Una hipótesis completamente inviable que crearía muchos más problemas de los que solucionaría. El segundo escenario, mucho más complejo, consistiría en que el Consejo Europeo se encontrase con la necesidad de arbitrar una solución no sólo para el "caso irlandés", sino para otros países como la República Checa o Polonia. En tal caso, las variables en juego aumentarían y el contenido de las negociaciones para salvar al Tratado de Lisboa sería, si cabe, aún más imprevisible.

Curiosamente, aunque el Tratado salvase todos estos obstáculos, y entrase finalmente en vigor, nos encontraríamos con un texto de valoración ambivalente. Desde luego, si el parámetro que se toma en consideración sigue siendo el frustrado Proyecto de Constitución, su regulación resultará decepcionante para los más europeístas, al no incorporar las propuestas y pretensiones más ambiciosas contenidas en aquel documento. Desde esa perspectiva el Tratado representará un retroceso, un paso hacia atrás. En cambio, si el elemento al que otorgamos mayor relevancia en la valoración de la significación del Tratado de Lisboa es a la profun- 
da incertidumbre en la que se ha encontrado anclado el proceso de construcción europea desde 2005, la conclusión no puede ser otra que la de que este nuevo Tratado supondría una salida al callejón. Es decir, un importante salto hacia adelante. La delicada situación creada tras el referéndum celebrado en Irlanda el 12 de junio de 2008 añade, si cabe, más argumentos a esta segunda opción interpretativa.

\section{DE B A T E}

Enelmomentodeconformarlapresente edición, la reforma energética y su constitucionalidadconstituíauntema desumaactualidadporsuimportancia, cargaideológicayconsecuenciaafuturoparaMéxico;poresemotivoconvocamosaunaseriedeacadémicosparaque debatieransobreeltema,cuyasopinionessereproducen porsuvalor,auncon el riesgo dequeel tema haya pasadoa un segundo plano mediático

\section{Razones, consideraciones} y preguntas sobre la reforma energética en México

\section{Consideraciones en torno a la reforma petrolera}

Paulino Ernesto Arellanes Jiménez

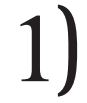

Cuando Lázaro Cárdenas no era todavía presidente y al recorrer el país como militar que era, se dio cuenta que las compañías pe-

\footnotetext{
* Doctor y catedrático de la Benemérita Universidad Autónoma de Puebla.
}

troleras extranjeras resguardaban el territorio de las instalaciones petroleras como si fueran extraterritorio y que por lo tanto, pasaba a ser territorio de los países de donde eran esas empresas, pero no de México; de manera que esto le causó una ingrata experiencia, de tal suerte que cuando llegó a ser presidente de la República la conciencia nacional le condujo a rescatar el bien público, como es el petróleo como patrimonio nacional, a pesar de toda la riqueza que ya habían explotado las empresas extranjeras sin ningún o poco beneficio para el país.

¿Cuál historia se repite, hoy que se está discutiendo más que debatiendo en torno a la reforma petrolera, la historia de antes de Cárdenas o la historia posterior? Creo que la derecha mexicana y el PAN le están apostando a la historia de antes, cuando las empresas extranjeras eran las propietarias (porque se adueñaron) del petróleo desde los Tratados de Bucareli hasta 1938; así ahora se pretende bajo el subterfugio" de "fortalecer" a Pemex concesionar los más importante: explotación, refinación 